This article was downloaded by: [AMS]

On: 29 April 2009

Access details: Access Details: [subscription number 789755461]

Publisher Taylor \& Francis

Informa Ltd Registered in England and Wales Registered Number: 1072954 Registered office: Mortimer House, 37-41 Mortimer Street, London W1T 3JH, UK

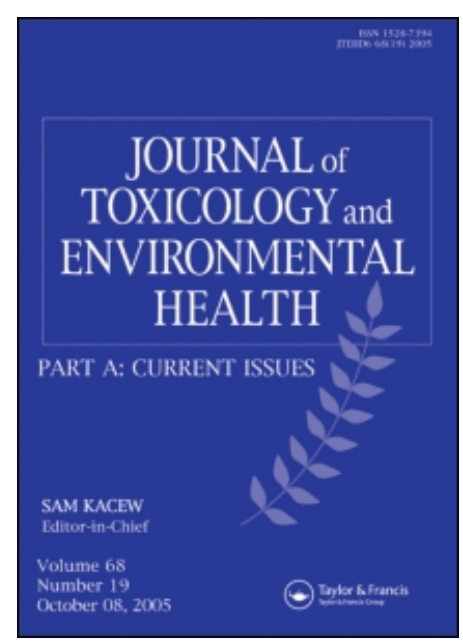

Journal of Toxicology and Environmental Health, Part A

Publication details, including instructions for authors and subscription information:

http://www.informaworld.com/smpp/title content=t713667303

\title{
Thioredoxin Overexpression Modulates Remodeling Factors in Stress \\ Responses to Cigarette Smoke
}

Yi-Ling Huang ab; Chun-Yu Chuang b; Fung-Chang Sung ac; Chia-Yang Chen a

a Institute of Environmental Health, College of Public Health, National Taiwan University, Taipei ${ }^{\mathrm{b}}$ Department of Biomedical Engineering and Environmental Sciences, National Tsing Hua University, Hsinchu ${ }^{\circ}$ Institute of Environmental Health, College of Public Health, China Medical University, Taichung, Taiwan

Online Publication Date: 01 January 2008

To cite this Article Huang, Yi-Ling, Chuang, Chun-Yu, Sung, Fung-Chang and Chen, Chia-Yang(2008)'Thioredoxin Overexpression Modulates Remodeling Factors in Stress Responses to Cigarette Smoke',Journal of Toxicology and Environmental Health, Part A,71:22,1490 - 1498

To link to this Article: DOI: $10.1080 / 15287390802350030$

URL: http://dx.doi.org/10.1080/15287390802350030

\section{PLEASE SCROLL DOWN FOR ARTICLE}

Full terms and conditions of use: http://www.informaworld.com/terms-and-conditions-of-access.pdf

This article may be used for research, teaching and private study purposes. Any substantial or systematic reproduction, re-distribution, re-selling, loan or sub-licensing, systematic supply or distribution in any form to anyone is expressly forbidden.

The publisher does not give any warranty express or implied or make any representation that the contents will be complete or accurate or up to date. The accuracy of any instructions, formulae and drug doses should be independently verified with primary sources. The publisher shall not be liable for any loss, actions, claims, proceedings, demand or costs or damages whatsoever or howsoever caused arising directly or indirectly in connection with or arising out of the use of this material. 


\title{
Thioredoxin Overexpression Modulates Remodeling Factors in Stress Responses to Cigarette Smoke
}

\author{
Yi-Ling Huang ${ }^{1,2}$, Chun-Yu Chuang ${ }^{2}$, Fung-Chang Sung ${ }^{1,3}$, and Chia-Yang Chen ${ }^{1}$ \\ ${ }^{1}$ Institute of Environmental Health, College of Public Health, National Taiwan University, Taipei, \\ ${ }^{2}$ Department of Biomedical Engineering and Environmental Sciences, National Tsing Hua University, \\ Hsinchu, and ${ }^{3}$ Institute of Environmental Health, College of Public Health, China Medical University, \\ Taichung, Taiwan
}

\begin{abstract}
Cigarette smoke (CS) generates reactive oxygen species (ROS) to produce oxidative damage of bronchial epithelial cells. Prolonged repair responses lead to airway remodeling and irreversible airflow limitation. Thioredoxin (TRX) is a redox protein that scavenges ROS to prevent oxidative stress. The aim of this study was to investigate the mechanisms underlying TRX-mediated CS-induced stress relevant to airway remodeling. Results showed that CS stimulated ROS generation and apoptosis in normal human bronchial epithelial (BEAS-2B) cells, and interfered with gene expression of remodeling factors, such as activation of transforming growth factor (TGF)- $\beta 1$, epidermal growth factor receptor (EGFR), and cyclin-dependent kinase inhibitor (p21), but repressed matrix metalloproteinases (MMP)-9. In particular, TRX-overexpressing bronchial epithelial (TRX-TD) cells reduced CS-induced apoptosis, and suppressed airway remodeling through attenuation of TGF- $\beta 1$, EGFR, and p21 and upregulation of MMP-9 expression. TGF- $\beta 1$ was shown to regulate MMP-9 as evidenced by suppression of MMP-9 protein induction by TGF- $\beta 1$ antibody. In addition, CS produced apoptosis of BEAS-2B cells via TRX oxidation, which activated signal transduction factors, including apoptosis signalregulating kinase (ASK) 1 and c-Jun N-terminal kinase (JNK). In contrast, TRX-TD cells exposed to CS retained reduced-form TRX, and inactivated ASK1 and JNK to attenuate apoptosis. This study indicated TRX overexpression was involved in CS-induced apoptosis and prevented airway remodeling through ASK1-JNK inactivation and MMP-9 augmentation.
\end{abstract}

In biological organisms, oxidation-reduction (redox) reactions occur dynamically during metabolism. However, imbalance of redox reaction produces oxidative stress and results in cell injury, inflammation, and tissue damage. Cigarette smoke (CS)

Received 2 June 2008; accepted 15 July 2008.

This study received funding from National Science Council Taiwan (NSC 95-2314-B-007-005).

Address correspondence to Dr. Chun-Yu Chuang, Department of Biomedical Engineering and Environmental Sciences, National Tsing Hua University, 101, section 2, Kuang-Fu Road, Hsinchu 30013, Taiwan. E-mail: cychuang@mx.nthu.edu.tw is one of the major external sources of reactive oxygen species (ROS) relevant to human lung diseases. Because of the multiple compounds and complexes in CS (Hoffmann \& Hoffmann, 1997), tobacco smoking may produce lung inflammation (Hellermann et al., 2002), chronic obstructive pulmonary diseases (Wald \& Hackshaw, 1996), and even lung cancer (Hecht, 2003).

Airway epithelium provides a protective barrier against external environments. Several in vitro studies demonstrated CS extract induces oxidative stress and results in apoptosis or necrosis (Banzet et al., 1999; Carnevali et al., 2003). Damaged epithelial cells may prolong the period of epithelial repair and express remodeling mediators, such as growth factors and matrix metalloproteinases (MMP) that contribute to structural changes in bronchial epithelium (i.e., airway remodeling) (Hamilton et al., 2003). This remodeling produces irreversible airflow limitation and increased airway hyperresponsiveness (James et al., 1989). Gene expression of several growth factors including transforming growth factor (TGF)- $\beta 1$, epidermal growth factor receptor (EGFR), and cyclin-dependent kinase inhibitor (p21) are increased in inflammatory responses. MMP induce digestion of basement membranes to prevent airway inflammation (Yoon et al., 2007) and tumor progression (Martin \& Matrisian, 2007).

Thioredoxin (TRX), a known antioxidant with redox active sequence Cys-Gly-Pro-Cys, is ubiquitous in mammals (Hirota et al., 2002; Holmgren, 1985). TRX regulates cellular redox balance, promotes cell growth, inhibits apoptosis, and modulates inflammation (Nakamura et al., 2005; Watson et al., 2004). TRX is presumed to be essential for cell survival, as knockout mice lacking TRX do not survive (Powis \& Montfort, 2001; Nonn et al., 2003). Because of the stress-inducible characteristics, TRX is expressed in response to $\mathrm{CS}$, ROS, ionization radiation, and air pollutants (Hirota et al., 2002; Nakamura et al., 1997; Powis \& Montfort, 2001). Genetic suppression or inhibition of TRX results in increased ROS generation and apoptosis (Hansen et al., 2006). In TRX transgenic mice there is decreased alveolar 
damage from hyperoxia-induced apoptosis (Yamada et al., 2007), and suppressed systemic inflammatory responses in response to CS (Sato et al., 2006).

Cells respond to ROS-induced apoptosis via a variety of signal transduction pathways (Tesfaigzi, 2006). The mitogenactivated protein kinase (MAPK) family regulates growth signaling in response to stresses (Wada \& Penninger, 2004). Subgroups of the MAPK pathway, c-Jun N-terminal kinase (JNK) and p38 MAPK, show stress-activated characteristics and regulate cell survival or apoptosis. JNK is required for stress-induced apoptosis of normal cells. Further, apoptosis signal-regulating kinase (ASK) 1 is activated by ROS involved in apoptosis, and upregulates $\mathrm{p} 38$ and JNK expression (Tobiume et al., 2001). Thus, MAPK plays a crucial role in cell proliferation and apoptosis in response to oxidative stress. However, the signaling transduction resulting from CS exposure in airway epithelial cells is still not completely understood.

CS generates ROS leading to airway remodeling in bronchial epithelium. Once transformed, the remodeled lung is resistant to therapy (Yamauchi \& Inoue, 2007); thus, it is necessary to understand the mechanisms underlying TRX mediated CSinduced apoptosis and airway remodeling. In this study, a TRX-overexpressing bronchial epithelial (TRX-TD) cell line was constructed to examine how TRX-mediated expression of remodeling factors in human bronchial epithelial cells is affected by CS-induced oxidative stress.

\section{METHODS}

\section{Cell Culture}

Normal human bronchial epithelial cells, BEAS-2B (ATCC CRL-9609), were grown on coated tissue culture plates (a mixture of $0.01 \mathrm{mg} / \mathrm{ml}$ fibronetin, $0.03 \mathrm{mg} / \mathrm{ml}$ vitrogen 100 , and $0.01 \mathrm{mg} / \mathrm{ml}$ bovine serum albumin in $10 \mathrm{ml}$ LHC-9 medium) in LHC-9 medium (Invitrogen, Carlsbad, CA). LHC-9 medium is a serum-free medium supplemented with $0.5 \mathrm{ng} / \mathrm{ml}$ recombinant epidermal growth factor, $500 \mathrm{ng} / \mathrm{ml}$ hydrocortisone, $0.005 \mathrm{mg} / \mathrm{ml}$ insulin, $0.035 \mathrm{mg} / \mathrm{ml}$ bovine pituitary extract, $500 \mathrm{n} M$ ethanolamine, $500 \mathrm{n} M$ phosphoethanolamine, $0.01 \mathrm{mg} / \mathrm{ml}$ transferrin, $6.5 \mathrm{ng} / \mathrm{ml}$ 3,3',5-triiodothyronine, $500 \mathrm{ng} / \mathrm{ml}$ epinephrine, 0.1 $\mathrm{ng} / \mathrm{ml}$ retinoic acid, and trace elements.

\section{Plasmid Construction of TRX Gene-Tagged Flag}

Human TRX cDNA was prepared by polymerase chain reaction (PCR) based on the sequence derived from the NCBI (NM_003329). The TRX was flag-tagged in a p3XFlag-CMV-14 vector (between the restriction sites BamHI and SalI) according to the manufacturer's recommended protocol (Sigma, St. Louis, MO). After sequence verification, the C-terminal of the TRX gene-attached 3flag was inserted into a tetracycline-controllable pTRE $_{2}$ hyg vector (BD Biosciences, San Jose, CA) through restriction enzymes catalysis of ClaI and SalI (for identification of exogenous TRX expression). The plasmid pTRE $_{2}$ hyg-TRX-3flag was then transfected into DH5 $\alpha$ competent cells (Invitrogen, Carlsbad, CA). The presence of the plasmid DNA was verified by restriction endonuclease digestion and agarose gel electrophoresis.

\section{TRX Overexpression in BEAS-2B Cells}

BEAS-2B cells were transfected with the pTet-on regulator plasmid DNA by lipofectamine and OPTI-MEM I medium (Invitrogen, Carlsbad, CA) following the manufacturer's protocol. After selection with $1 \mathrm{mg} / \mathrm{ml} \mathrm{G} 418$ (Sigma, St. Louis, $\mathrm{MO}$ ) for approximately $2 \mathrm{mo}$, the pTRE $\mathrm{T}_{2}$ hyg-TRX-3flag plasmid DNA was transfected into the established Tet-on regulator expression BEAS-2B cells. After G418 selection, the BEAS-2B Tet-on pTRE $_{2}$ hyg-TRX-3flag cells were developed, and overexpressed TRX (via Tet-on system) was switched on by $2 \mu \mathrm{g} / \mathrm{ml}$ doxycycline for $24 \mathrm{~h}$. The TRX-overexpressing cells (TRX-TD; doxycycline-induced BEAS-2B Tet-on pTRE ${ }_{2}$ hyg-TRX-3flag cells) were examined for the expression of human flag mRNA and protein, respectively, by quantitative real time PCR and flow cytometric analysis.

\section{Insulin Reduction Assay}

Dithiothreitol (DTT; Sigma, St. Louis, MO) was used as a reductant in the insulin reduction assay as described (Wollman et al. 1988). The reaction reagents were composed of $130 \mu M$ insulin (soluble at $\mathrm{pH} \mathrm{2-3}$ and adjusted to $\mathrm{pH} 8$ ), $100 \mathrm{mM}$ potassium phosphate ( $\mathrm{pH}$ 7), $2 \mathrm{mM}$ ethylenediamine tetraacetic acid (EDTA), and $2 \mathrm{~m} M$ DTT. The protein level of constructed TRX-3flag expression in BEAS-2B cells was purified by immunoprecipitation using anti-flag antibody $(\mathrm{Ab})$ and protein G-agarose (Sigma, St. Louis, MO). The competitive assay of TRX reduction capability was detected with DTT at $650 \mathrm{~nm}$, kinetic 1-min intervals for $2 \mathrm{~h}$. TRX protein from Escherichia coli (Sigma, St. Louis, MO) was used as a positive control.

\section{Intracelluar TRX-Flag Immunostaining}

The expression of exogenous transfected TRX was monitored by intracellular flag immunostaining. TRX-TD cells were fixed with commercial fixation solution (eBioscience, San Diego, $\mathrm{CA}$ ), vortexed, incubated in the dark at room temperature for $20 \mathrm{~min}$, and permeated for staining (permeabilization buffer, eBioscience, San Diego, CA). Optimal concentration of monoclonal M2 anti-flag-FITC Ab (Sigma, St. Louis, MO) was added to cells and determined by flow cytometry (CyFlow, Partect). The data were analyzed using WinMDI 2.8 software.

\section{Western Blotting}

Cells were lysed with protein extract buffer containing $0.6 M \mathrm{KCl}, 1 \%$ Triton X-100, $0.02 M$ Tris- $\mathrm{HCl}(\mathrm{pH} 7), 1 \mathrm{mM}$ phenylmethylsulfonyl fluoride, and $50 \mu \mathrm{g} / \mathrm{ml}$ aprotinin (all from 
Sigma, St. Louis, MO) and centrifuged at $8000 \times \mathrm{g}\left(3 \mathrm{~min}, 4^{\circ} \mathrm{C}\right)$. Protein samples in the supernatant were immediately transferred and the concentration was measured using a DC protein assay (Bio-Rad, Hercules, CA) according to Bradford (1976). For Western analysis of TRX redox status, the lysates were incubated with alkylated 4-acetamido-4'-maleimidylstilbene-2,2'-disulfonic acid (Molecular Probes, Eugene, OR) followed by nonreducing Western blot to distinguish between reduced (alkylated) and oxidized (nonalkylated) proteins (Chen et al., 2006). Protein in the samples were then electrophoresed over a $12.5 \%$ sodium dodecyl sulfate polyacrylamide gel, and subsequently transferred to a nitrocellulose membrane (Millipore, Billerica, MA). The membrane-bound proteins were then immunostained with antihuman TRX (Abcam, Cambridge, MA), flag (Sigma, St. Louis, MO), MMP-9 (R \& D Systems, Inc., Minneapolis, MN), and phospho-ASK1, phospho-JNK, or $\beta$-tubulin (Cell Signaling, Danvers, MA) Ab, followed by treatment with secondary anti-IgG horse radish peroxidase (HRP) Ab (Chemicon, Billerica, MA). Any tagged proteins were then detected using a chemiluminescence reagent (Perkin Elmer, Boston) and photographed in a G:Box ChemiXT 16 system (Syngene, Frederick, MD).

\section{Cigarette Smoke Extraction and Exposure}

CS extract was prepared as described by Hoshino et al. (2001). Mainstream smoke of 7 research-use cigarettes (University of Kentucky 2R4F; $10 \mathrm{mg}$ tar and $0.8 \mathrm{mg}$ nicotine per cigarette) was withdrawn steadily via a peristaltic pump at a rate of $50 \mathrm{rpm}$ and bubbling through a $27.5-\mathrm{cm}$ height vessel containing $10 \mathrm{ml}$ LHC-9 medium. CS extract consisted of multiple compounds with maximal absorbance at $305 \mathrm{~nm}$ wavelength; the concentration of $100 \%$ CS extract has a 0.5 absorbance at $305 \mathrm{~nm}$. In order to quantify and reproduce the daily preparation of CS extract, the absorbance at $305 \mathrm{~nm}$ was measured for CS content. The CS extract freshly obtained was then filtered through a $0.22-\mu \mathrm{m}$ filter, and diluted to the desired percentage prior to cell exposure.

\section{Cell Viability Assay}

LIVE/DEAD assay (Molecular Probes, Invitrogen, Carlsbad, CA) was carried out as per manufacturer protocol. In brief, CS-exposed cultures were washed once with $200 \mu \mathrm{l} /$ well of phosphate-buffered saline (PBS) (for 96 well plates), and $100 \mu 1$ phosphate-buffered saline (PBS) was added back to the cells. Then $100 \mu$ of $4 \mu M$ calcein and $2 \mu M$ ethidium homodimer-1 mixture was added to cells in dark. After 30 min of incubation at $37^{\circ} \mathrm{C}$, cells were detected with fluorescence of calcein and ethidium homodimer-1 at excitation/emission wavelengths $485 / 538 \mathrm{~nm}$ and 538/620 nm separated into live or dead cells.

\section{Measurement of Intracellular ROS Generation}

Cells were incubated with $5 \mu M$ CM- ${ }_{2}$ DCFDA (5,6chloromethyl-2', $7^{\prime}$-dichlorodihydrofluorescein diacetate acetyl ester; Molecular Probes, Invitrogen Corporation, Carlsbad, $\mathrm{CA}$ ) for $30 \mathrm{~min}$. CM- $\mathrm{H}_{2}$ DCFDA is a cell-permeant and nonfluorescent compound when reduced, and emits fluorescence when oxidized by ROS (hydrogen peroxide and hydroxyl radical). The adherent cells were trypsinized, washed with PBS three times, and then resuspended in $1 \mathrm{ml}$ PBS. The fluorescent signal reflecting ROS was determined by flow cytometry. Data analysis was performed using WinMDI 2.8 software.

\section{Apoptosis Determination}

The level of apoptosis was determined using an Annexin V-FITC apoptosis detection kit (R \& D Systems, Inc., Minneapolis, MN). The trypsinized cells were washed twice with cold PBS and resuspended in 18 binding buffer. One hundred microliters of suspension of $10^{5}$ cells was treated $5 \mu \mathrm{l}$ Annexin V. The staining cells were incubated at $4^{\circ} \mathrm{C}$ in the dark for $15 \mathrm{~min}$ and $400 \mu \mathrm{l}$ binding buffer was added before FACS analysis. The fluorescent signal of flow cytometry was performed by WinMDI 2.8 software. The percent apoptosis was referred to sham groups within $95 \%$ confidence intervals of intensity.

\section{Reverse-Transcription Polymerase Chain Reaction (RT-PCR)}

Total RNA were extracted using RNA Trizol (Invitrogen, Carlsbad, CA) reagent to determine the gene expression at mRNA level by quantitative real-time PCR. cDNA was synthesized from total RNA by reverse transcription with oligo-dT primer and RNase-free water at $65^{\circ} \mathrm{C}$ for $5 \mathrm{~min}(1 \mathrm{cycle})$ to anneal primer with mRNA. After that, the product was reversetranscribed to cDNA with M-MLV reverse transcriptase (Invitrogen, Carlsbad, CA) and dNTP at $37^{\circ} \mathrm{C}$ for $90 \mathrm{~min}$ and $70^{\circ} \mathrm{C}$ for $15 \min (1$ cycle).

\section{Quantitative Real-Time PCR}

Real-time PCR was performed to quantify the message expression pattern of RT-PCR-synthesized cDNA products. One hundred nanograms cDNA was analyzed using $2 \times$ power SYBR Green PCR master mix, forward and reverse primers, and RNase-free water by an ABI 7300 sequence detection system (Applied Biosystems, Inc., Foster City, CA). PCR primers were: TRX sense $5^{\prime}$-GGA CGC TGC GGG TGA TA- $3^{\prime}$ and anti-sense 5'-GAG AGG GAA TGA AAG AAA GGC TT-3'; TGF- $\beta 1$ sense $5^{\prime}$-ACA ATT CCT GGC GAT ACC TCA-3' and anti-sense 5'-GGC GAA AGC CCT CAA TTT C-3'; EGFR sense 5'-GGA GAG GAG AAC TGC CAG AAA CT-3' and anti-sense 5'-GCA GCC TGC AGC ACA CTG-3'; p21 sense $5^{\prime}$-GGG ACA GCA GAG GAA GAC CAT- ${ }^{\prime}$ ' and antisense 5'-GGA GTG GTA GAA ATC TGT CAT GCT-3'; MMP-9 sense $5^{\prime}$-ACC ACC TCG AAC TTT GAC AGC- $3^{\prime \prime}$ and anti-sense $5^{\prime}$-TCT AAG CCC AGC GCG TG-3'; $\beta$-actin sense 5'-TTG TTA CAG GAA GTC CCT TGC C- $3^{\prime}$ and anti-sense 5'-ATG CTA TCA CCT CCC CTG TGT G-3'. The reaction 
mixture was incubated $50^{\circ} \mathrm{C}$ for $2 \mathrm{~min}, 95^{\circ} \mathrm{C}$ for $10 \mathrm{~min}$, and $95^{\circ} \mathrm{C}$ for $15 \mathrm{~s}, 52^{\circ} \mathrm{C}$ for $30 \mathrm{~s}, 72^{\circ} \mathrm{C}$ for $45 \mathrm{~s}$ for 40 cycles, with extension $95^{\circ} \mathrm{C}$ for $15 \mathrm{~s}$ and $60^{\circ} \mathrm{C}$ for $1 \mathrm{~min}$. The relative level of mRNA expression is a ratio of optical density of the experimental groups to that of $\beta$-actin. Independent triplicate experiments were performed.

\section{Statistical Analysis}

Results were described as mean \pm standard deviation of at least three separate experiments. All statistical analysis was conducted by the statistical package SPSS13.0. Statistically significant differences among groups were determined using Student's $t$-test and one-way analysis of variance (ANOVA). A two-tailed $p$ value $<.05$ was considered statistically significant.

\section{RESULTS}

\section{Constructed TRX Plasmid Expression in BEAS-2B Cells}

The reducing activity of TRX protein was determined by insulin reduction assay (Figure 1A). BEAS-2B cells were transfected the constructed TRX-3flag gene which expressed its protein and redox capability. In order to determine whether exogenous TRX transfection displayed in BEAS-2B cells, analysis of intracellular TRX-flag protein was conducted. Expression of TRX-flag protein in TRX-TD cells was significantly higher than BEAS-2B cells (intensity: $6 \pm 0.6$ and $15.4 \pm$ 1.9) (Figure 1B). The transgenic TRX-flag protein was detectable in TRX-TD cells but not BEAS-2B cells (Figure 1C). TRX-TD cells expressed both endogenous and exogenous TRX protein (Figure 1D). These results indicated that TRX-TD cells contained both endogenous and exogenous TRX, which led to overexpression of TRX.

\section{Cell Viability in CS Exposure}

CS served as the source of ROS in this study. BEAS-2B cells and TRX-TD cells were treated with different concentrations from 0 to $100 \% \mathrm{CS}$ for $24 \mathrm{~h}$ and then assessed for cell viability. The results illustrated a concentration-response relationship between CS exposure and cell viability (Figure 2). TRX-TD cells had a higher survival ratio than BEAS-2B cells following

(A)

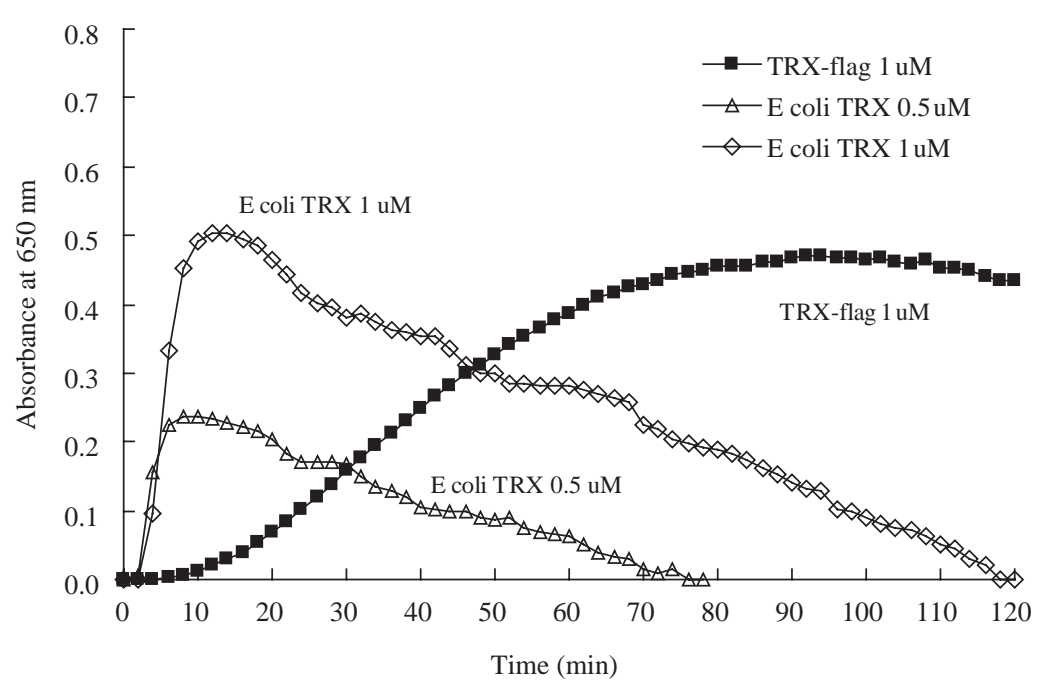

(B)

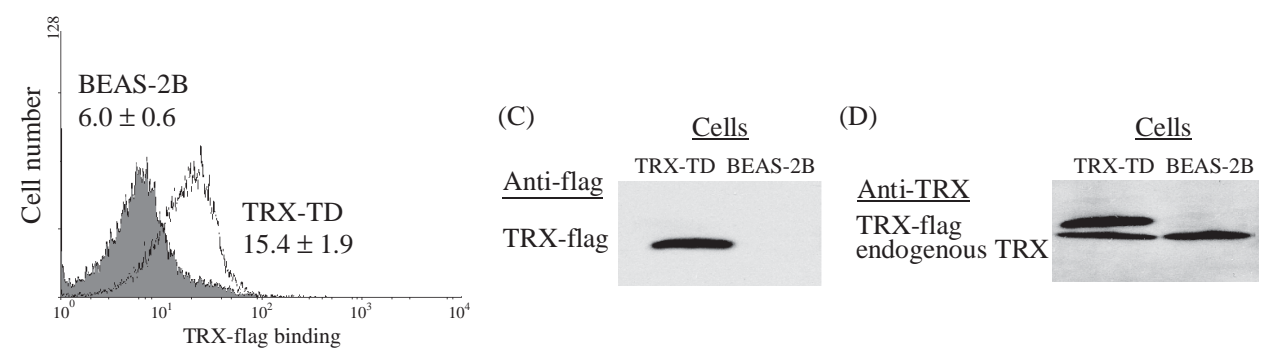

FIG. 1. Expression of TRX and TRX-flag protein in BEAS-2B and TRX-TD cells. (A) Reducing activity of TRX protein. (B) Cytometric analysis of intracellular TRX-flag protein. Data presented as mean \pm standard deviation of the intensity of fluorescence signal. Western blotting with (C) exogenous TRX-flag protein and (D) endogenous TRX protein. 


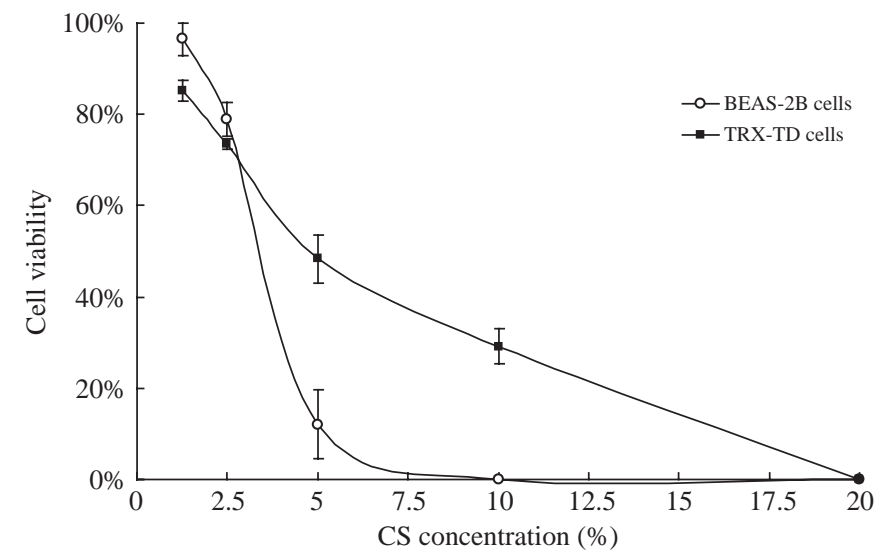

FIG. 2. Concentration response of cell viability in BEAS-2B and TRX-TD cells after 24-h CS exposure.

exposure to $5 \% \mathrm{CS}(48.4 \pm 4.3 \%$ and $12 \pm 6.8 \%)$. TRX-TD cells were more resistant to CS exposure than BEAS-2B cells. The survival ratio of cells exposed $2.5 \% \mathrm{CS}$ for $24 \mathrm{~h}$ was approximately $80 \%$, and thus the concentration of $2.5 \%$ CS for 24-h exposure was used for further experiments. At this concentration, cells displayed manifestations of oxidative stress but survived.

\section{TRX Overexpression Reduced ROS Generation and Apoptosis Following CS Exposure}

Treatment of BEAS-2B cells with a potent oxidant $500 \mu M$ $\mathrm{H}_{2} \mathrm{O}_{2}$ for $2 \mathrm{~h}$ was used as positive control of intracellular ROS generation (Figure 3A). A 24-h exposure to $2.5 \%$ CS was used to generate ROS in BEAS-2B cells. In contrast, TRX-TD cells over expressing TRX reduced ROS generation. CS-exposed BEAS-2B cells showed 1.43-fold increased mRNA expression in response to TRX referred compared to nonexposed BEAS2B cells (Figure 3B). TRX-TD cells expressed TRX 4.3-fold higher than BEAS-2B cells. CS exposure markedly induced 124.13-fold expression of TRX transcript in TRX-TD cells. This indicated that CS induced both endogenous and exogenous TRX expression. After CS exposure, TRX-TD cells (7\%) had a decreased level of apoptosis compared with BEAS-2B cells (11\%) (Figure 3C). TRX-TD cells overexpressing TRX suppressed CS-induced apoptosis.

\section{TRX Overexpression Mediated Inference of Remodeling Factors}

CS induced gene expression of TGF- $\beta 1$, EGFR, and $p 21$ in BEAS-2B cells compared to nonexposed BEAS-2B cells (6.89, 3.11 , and 1.65-fold increase, respectively) (Figure 4A). In contrast, CS suppressed the expression of MMP-9 (0.84-fold decrease). Further, following CS exposure TRX-TD cells displayed lower expression of TGF- $\beta 1$ and EGFR than BEAS-2B cells (respectively, fold changes 1.27 vs. 6.89 and 1.59 vs. 3.11), and repressed
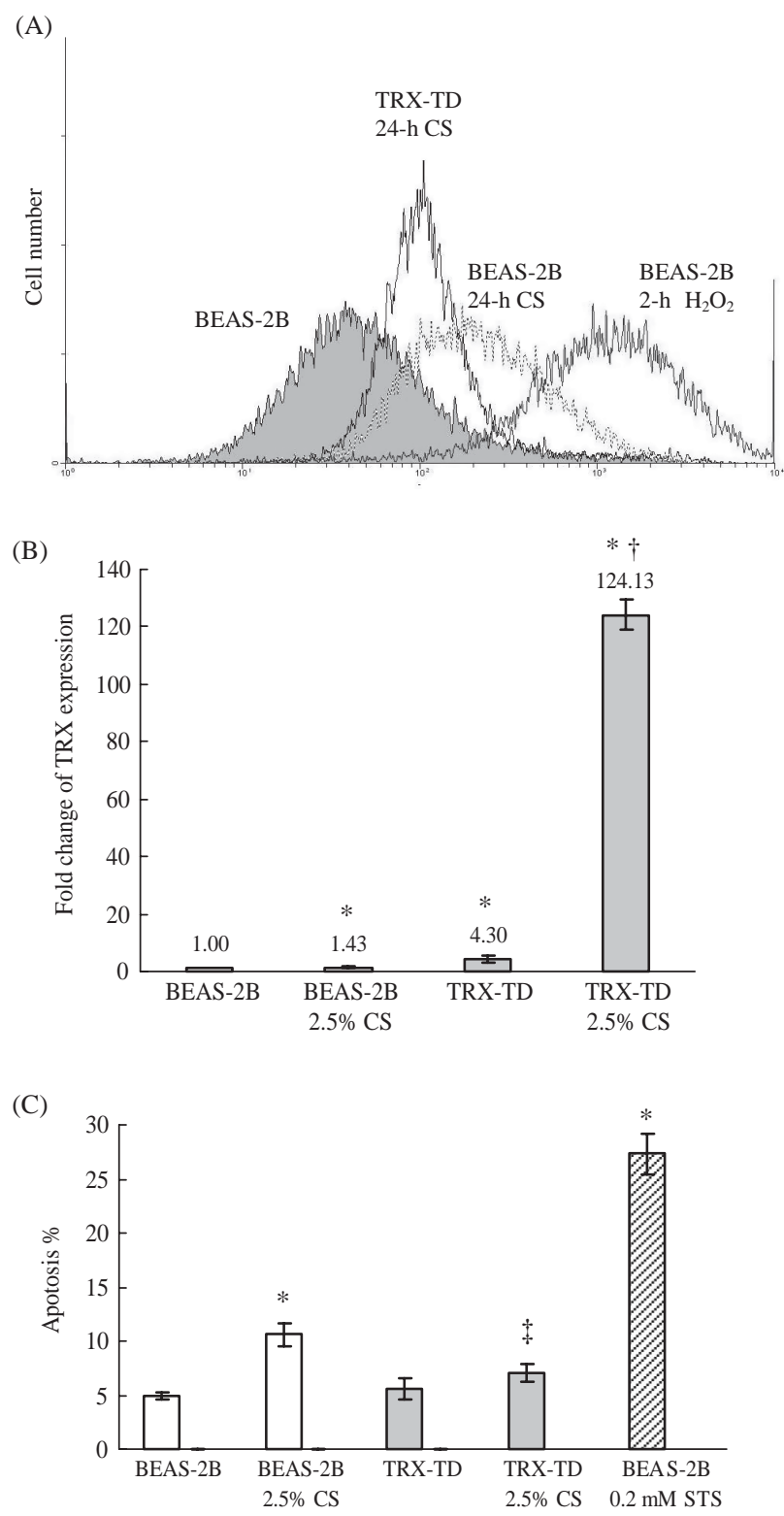

FIG. 3. Intracellular ROS generation, TRX expression, and apoptosis following exposure to $2.5 \% \mathrm{CS}$ for $24 \mathrm{~h}$. (A) ROS generation in BEAS-2B and TRX-TD cells. BEAS-2B cells treated with $500 \mu M \mathrm{H}_{2} \mathrm{O}_{2}$ for $2 \mathrm{~h}$ as a positive control. (B) Quantification of TRX transcript by real-time PCR. (C) Determination of apoptosis with Annexin-V-FITC staining and FACS detector. STS: staurosporine produces mitochondria damage as positive control of apoptosis. Asterisk indicates significant at $p<.05$ compared with BEAS-2B cells; ${ }^{\dagger} p<.05$, compared with TRX-TD cells; ${ }^{\ddagger} p<.05$, compared with CS-exposed BEAS-2B cells.

p21 transcript (0.93 vs. 1.65). Otherwise, CS exposure augmented MMP-9 expression in TRX-TD cells (3.99-fold increase).

Following exposure to CS, MMP-9 protein was diminished in BEAS-2B cells but activated in TRX-TD cells (Figure 4B). To investigate whether TGF- $\beta 1$ regulated MMP- 9 , TGF- $\beta 1 \mathrm{Ab}$ was added to neutralize TGF- $\beta 1$ protein secreted into culture 

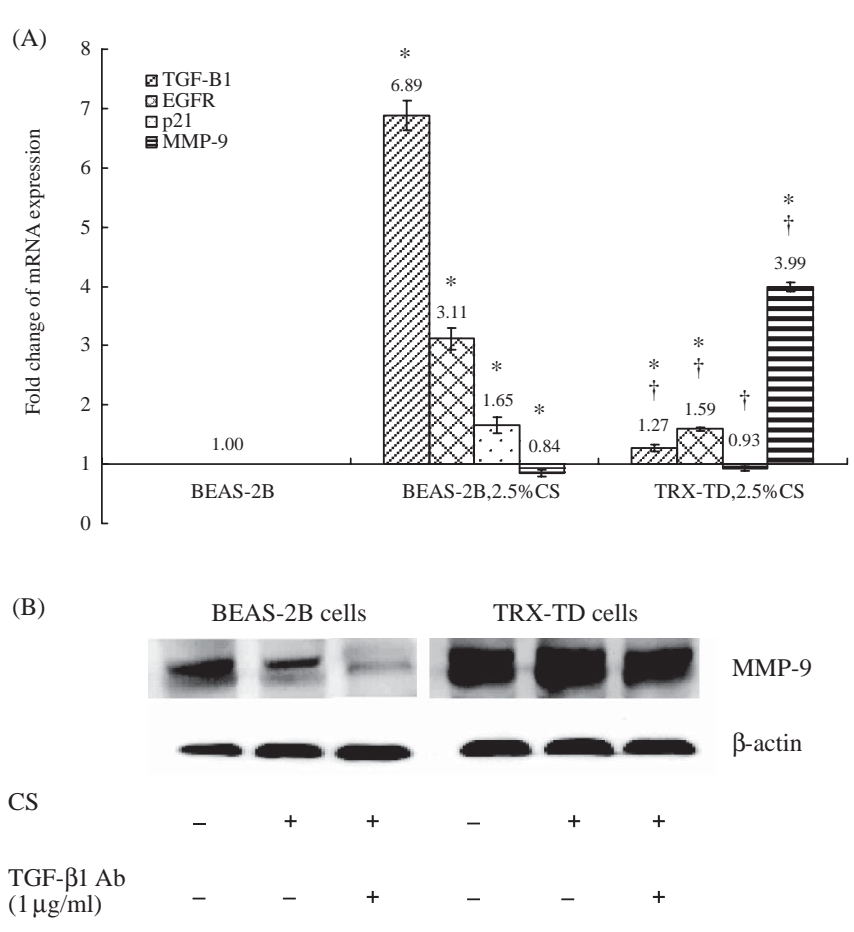

FIG. 4. Gene expression of remodeling factors in response to 24-h CS exposure. (A) Analysis of mRNA expression of TGF- $\beta 1$, EGFR, p21, and MMP-9 by real-time PCR. (B) Determination of MMP-9 protein using Western blotting. TGF- $\beta 1 \mathrm{Ab}$ was used to neutralize TGF- $\beta 1$ protein secreted into culture medium. Significant differences indicated by asterisk for $p<.05$, compared with BEAS-2B cells; ${ }^{\dagger} p<.05$, compared with CS-exposed BEAS$2 \mathrm{~B}$ cells.

medium. Interestingly, induction of MMP-9 protein was suppressed by adding TGF- $\beta 1 \mathrm{Ab}$.

\section{CS-Induced TRX and MAPK Expression}

CS induced TRX expression and oxidization (Figure 5). With respect to the activation of transfected TRX-flag, TRX-TD

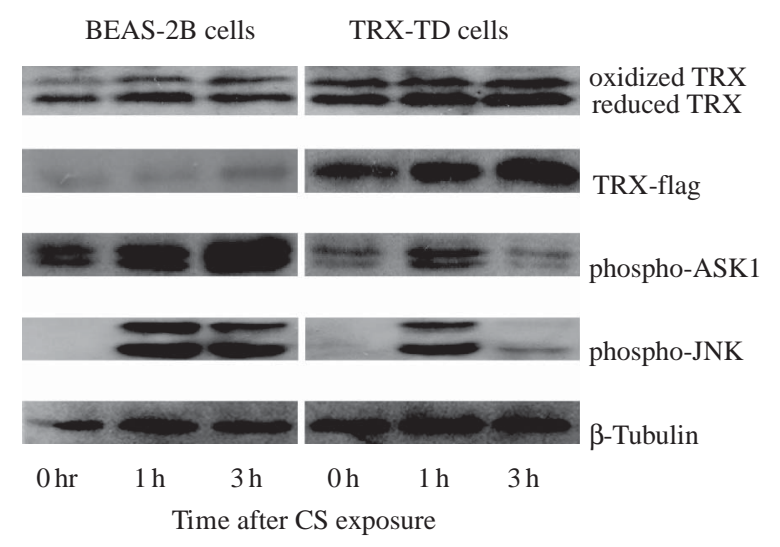

FIG. 5. Western blot analysis of redox TRX, TRX-flag, and phosphorylation of ASK1 and JNK in BEAS-2B and TRX-TD cells after CS exposure. cells contained higher amounts of reduced TRX than BEAS-2B cells following CS exposure. CS-exposed BEAS-2B cells displayed phosphorylation of ASK1 and JNK. In TRX-TD cells, phospho-ASK1 and phospho-JNK were activated following CS exposure, and subsequently TRX overexpression led to inactivation of phosphorylation.

\section{DISCUSSION}

CS is known to generate ROS in human lung epithelial cells (Ryter et al., 2007; Yao et al., 2007). This study investigated intracellular ROS generation and apoptosis in human bronchial epithelial cells following CS exposure. TRX possesses stressinducible characteristics to prevent cell injury and apoptosis following exposure to CS (Sato et al., 2006) and diesel exhaust particles (Kaimul Ahsan et al., 2005). Because of redox capability, TRX suppresses oxidative stress and inflammatory responses (Watson et al., 2004). Consistent with this study, TRX was upregulated in CS-exposed BEAS-2B cells and TRX-TD cells, enabling reduction of ROS generation and apoptosis. Data suggested that TRX overexpression protected airway cells against oxidative stress induced by CS.

TGF- $\beta$ plays a crucial rule in the signal network of cell growth and differentiation. TGF- $\beta$ inhibits cyclin D-dependent kinase 4 through induction of p21 pathway required for inhibition of cell growth (Massague et al., 2000). TGF- $\beta 1$ induces cell apoptosis which precedes inflammatory responses (Blobe et al., 2000). Yamasaki et al. (2008) showed that TGF- $\beta 1$ transgenic mice manifest marked bronchoalveolar and tissue inflammation, fibrosis, and pulmonary alveolar remodeling. Murillo et al. (2005) demonstrated that TGF- $\beta 1$ activates EGFR for anti-apoptosis and cell survival. Abnormal activation of EGFR suppressed apoptosis, enabling tumor progression (Liu et al., 2007), and this was found in lung cancer (Sharma et al., 2007). EGFR plays a direct role in pro-inflammatory responses by inducing interleukin (IL)-8 release from bronchial epithelial cells, which contribute to and prolong neutrophilic inflammation and tissue injury (Hamilton et al., 2003). Fedorov et al. (2005) demonstrated that the thickness of the lamina reticularis is significantly correlated with epithelial EGFR. EGFR impaired apoptosis and induced cell proliferation through increased p21 expression (Sheng et al., 2006).

TGF- $\beta 1$ stimulates the expression of MMP-9 for cell migration (Seomun et al., 2008). Airway epithelial wound repair enhances the activation of MMP-9 (Bove et al., 2007). MMP-9 induces digestion of basement membrane to prevent airway from remodeling. Yoon et al. (2007) found that MMP-9 exerted a protective capability during ozone-induced lung neutrophilic inflammation and hyperpermeability. The quantitative PCR results in the current study indicated that CS induced TGF- $\beta 1$, EGFR, and p21 expression in BEAS-2B cells but diminished MMP-9 expression. Evidence indicated that CS exposure activated TGF- $\beta 1$ and EGFR expression to initiate cellular responses, such as apoptosis and cell proliferation. 
TGF- $\beta 1$ mediates $\mathrm{p} 21$ to arrest cell cycle and inhibit apoptosis (Gartel \& Tyner, 2002). In particular, p21 blocks cell apoptosis by interacting with pro-apoptotic molecules such as ASK1, procaspase-3 and caspase-8. However, the results here suggested that induction of $\mathrm{p} 21$ was not sufficient for antiapoptosis, and thus resulted in activated ASK1 phosphorylation. The regulation of TGF- $\beta 1$ and $\mathrm{p} 21$ failed to protect airway cells from effects of CS, and thus led to cell apoptosis. Furthermore, expression of MMP-9 in BEAS-2B cells was suppressed by CS exposure, which would result in the progression of airway remodeling.

TRX is involved in cell growth and differentiation (Arner \& Holmgren, 2000), and regulation of tumor suppressor p53 to transactivate p21 (Ueno et al., 1999). p21 is an essential factor of cell cycle progression, DNA repair, and apoptosis (Harper et al., 1993; Xiong et al., 1993). Data of this study showed that TGF- $\beta 1$ activated EGFR to upregulate $\mathrm{p} 21$ for damage repair in CS-exposed BEAS-2B cells. Otherwise, TRX-TD cells reduced the transcript level of TGF- $\beta 1$ to prevent CS-induced apoptosis, and inhibited irregular cell proliferation and repair by downregulating EGFR and p21 expression. Expression of TGF- $\beta 1$, EGFR, and p 21 was preserved at steady state after CS exposure, which indicated TRX overexpression was involved in homeostatic mechanisms adequate to suppress CS-induced stress. This finding suggested that TRX might reduce gene expression of TGF- $\beta 1$, EGFR, and p21 to eliminate the influence of any irregular cell proliferation of extracellular matrices in airway epithelial cells. In contrast, TRX overexpression enhanced MMP-9 transcription in TRX-TD cells. Upregulation of MMP-9 is thought to modulate airway remodeling (Ohbayashi \& Shimokata, 2005), and likely to exert a protective role for bronchial epithelial cells in response to CS exposure. In addition, activation of MMP-9 protein was suppressed by treatment with an anti-TGF- $\beta 1 \mathrm{Ab}$, which suggested that the presence of TGF- $\beta 1$ appeared to neutralize CS-induced mediators in the medium, and attenuated the generation of MMP-9 protein.

TRX regulates the ROS-induced MAPK pathway (Hsieh \& Papaconstantinou, 2006). When TRX is oxidized, ASK1 becomes active, and cells approach apoptosis by upregulation of downstream JNK and p38 expression (Yoshida et al., 2003). JNK is important for induction of apoptosis. Inhibition of JNK signal expression would abrogate apoptosis from oxidative injury. Lee et al. (2002) found that TRX mediates JNK expression. MAPK was induced by CS following acute exposure (Yoneda et al., 2003). In present study, CS exposure oxidized TRX to activate ASK1 and JNK in BEAS-2B cells, and resulted in apoptosis. Otherwise, TRX-TD cells normally express TRX and ASK1 at steady state. When exposed to CS, TRX-TD cells were found to overexpress TRX and attenuate phosphorylation of ASK1 and JNK. This indicated a fraction of TRX was oxidized early, and the reduced form was retained to inactivate ASK1 phosphorylation and suppress apoptosis. Therefore, TRX overexpression protected airway cells from ASK1-activated apoptosis through inhibition of JNK pathway.
MAPK signaling is related to EGFR expression. EGF induces MAPK signaling and proliferation in pulmonary epithelial cells (Semlali et al., 2008). Furthermore, MMP-9 is MAPK dependent and regulated by TGF- $\beta 1$ and EGFR (Uttamsingh et al., 2007). TRX ameliorates CS-induced lung inflammation and emphysema (Sato et al., 2008). Based on previous studies and our findings, Figure 6 presents an illustration of how TRX mediates remodeling factors following CS exposure. In general, CS-stimulated ROS generation induces expression of TGF- $\beta 1$ and EGFR to activate $\mathrm{p} 21$ and ASK1-JNK signaling for cell repair and apoptosis. Damaged epithelial cells may prolong the period of epithelial repair and contribute to airway remodeling. When TRX overexpression occurs following CS exposure, p21 and ASK1JNK signaling are repressed, and MMP-9 is upregulated for inhibition of apoptosis and remodeling. TRX overexpression exerts the capacity to protect human airway epithelial cells against oxidative stress from CS.

Oxidative stress generated by CS induced MAPK phosphorylation and suppressed MMP-9 expression, leading to apoptosis

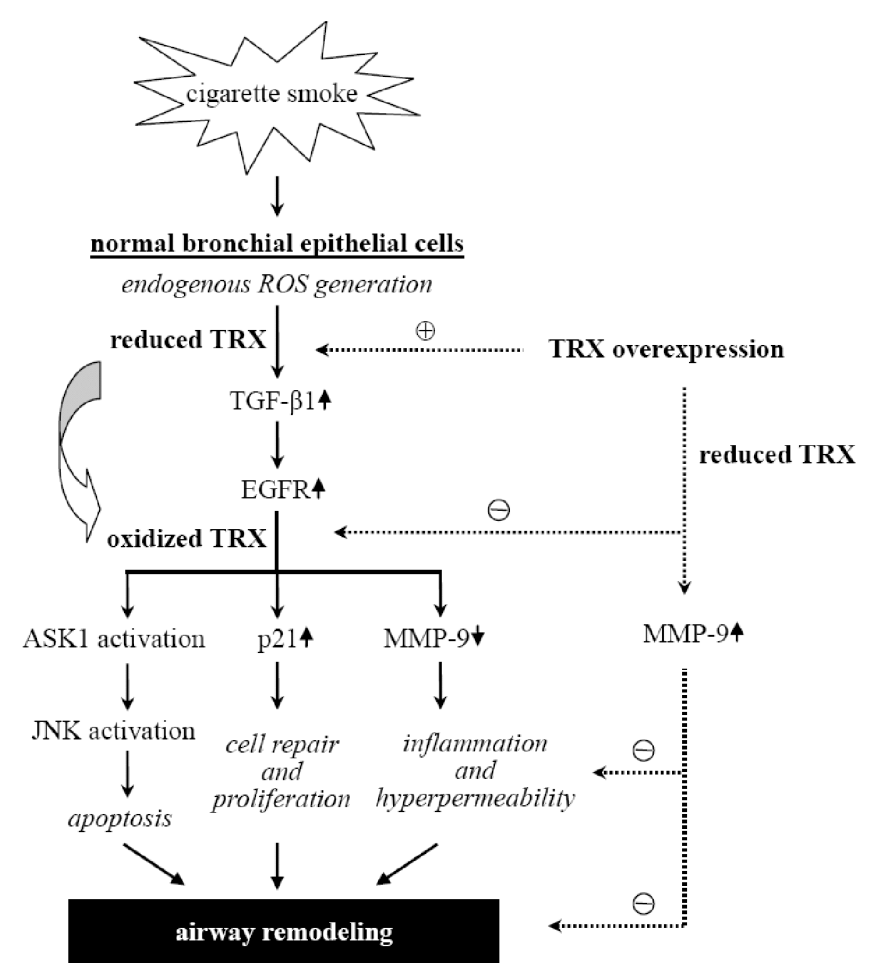

FIG. 6. An illustration of TRX mediating stress response to CS. CS induces airway epithelial cells to generate ROS, and upregulates the expression of TGF- $\beta 1$ and EGFR to activate p21 and ASK1-JNK signaling for cell repair and apoptosis. Sloughed epithelial cells are involved in airway remodeling due to irregular cell proliferation and prolonged repair duration. During TRX overexpression, TRX is partially oxidized to modulate CSinduced oxidative stress, and the reduced form of TRX is retained to repress p21 and ASK1-JNK signaling and augment MMP-9 expression for diminished inflammation and hyperpermeability. Data suggest TRX modulates CS-induced stress to retard apoptosis and progression of airway remodeling in bronchial epithelial cells. 
and progression of airway remodeling. TRX is a ubiquitous protein playing a role in signal transduction. This study demonstrated that transfected TRX produced redox effects and transcription/translation responses in human airway cells. TRX overexpression prevented airway cells from CS-induced apoptosis and remodeling through ASK1-JNK inactivation and MMP-9 augmentation.

\section{REFERENCES}

Arner, E. S., and Holmgren, A. 2000. Physiological functions of thioredoxin and thioredoxin reductase. Eur. J. Biochem. 267:6102-6109.

Banzet, N., Francois, D., and Polla, B. S. 1999. Tobacco smoke induces mitochondrial depolarization along with cell death: Effects of antioxidants. Redox. Rep. 4:229-236.

Blobe, G. C., Schiemann, W. P., and Lodish, H. F. 2000. Role of transforming growth factor beta in human disease. N. Engl. J. Med. 342:1350-1358.

Bove, P. F., Wesley, U. V., Greul, A. K., Hristova, M., Dostmann, W. R., and van der Vliet, A. 2007. Nitric oxide promotes airway epithelial wound repair through enhanced activation of MMP-9. Am. J. Respir. Cell Mol. Biol. 36:138-146.

Bradford, M. M. 1976. A rapid and sensitive method for the quantitation of microgram quantities of protein utilizing the principle of protein-dye binding. Anal. Biochem. 72:248-254.

Carnevali, S., Petruzzelli, S., Longoni, B., Vanacore, R., Barale, R., Cipollini, M., Scatena, F., Paggiaro, P., Celi, A., and Giuntini, C. 2003. Cigarette smoke extract induces oxidative stress and apoptosis in human lung fibroblasts. Am. J. Physiol. Lung Cell Mol. Physiol. 284:L955-L963.

Chen, Y., Cai, J., and Jones, D. P. 2006. Mitochondrial thioredoxin in regulation of oxidant-induced cell death. FEBS Lett. 580:6596-6602.

Fedorov, I. A., Wilson, S. J., Davies, D. E., and Holgate, S. T. 2005. Epithelial stress and structural remodelling in childhood asthma. Thorax 60:389-394.

Gartel, A. L., and Tyner, A. L. 2002. The role of the cyclin-dependent kinase inhibitor p21 in apoptosis. Mol. Cancer Ther. 1:639-649.

Hamilton, L. M., Torres-Lozano, C., Puddicombe, S. M., Richter, A., Kimber, I., Dearman, R. J., Vrugt, B., Aalbers, R., Holgate, S. T., Djukanović, R., Wilson, S. J., and Davies, D. E. 2003. The role of the epidermal growth factor receptor in sustaining neutrophil inflammation in severe asthma. Clin. Exp. Allergy 33:233-240.

Hansen, J. M., Go, Y. M., and Jones, D. P. 2006. Nuclear and mitochondrial compartmentation of oxidative stress and redox signaling. Аnпи. Rev. Pharmacol. Toxicol. 46:215-234.

Harper, J. W., Adami, G. R., Wei, N., Keyomarsi, K., and Elledge, S. J. 1993. The p21 Cdk-interacting protein Cip1 is a potent inhibitor of G1 cyclin-dependent kinases. Cell 75:805-816.

Hecht, S. S. 2003. Tobacco carcinogens, their biomarkers and tobacco-induced cancer. Nat. Rev. Caner 3:733-744.

Hellermann, G. R., Nagy, S. B., Kong, X., Lockey, R. F., and Mohapatra, S. S. 2002. Mechanism of cigarette smoke condensate-induced acute inflammatory response in human bronchial epithelial cells. Respir. Res. 3:22-29.

Hirota, K., Nakamura, H., Masutani, H., and Yodoi, J. 2002. Thioredoxin superfamily and thioredoxin-inducing agents. Ann. NY Acad. Sci. 957:189-199.

Hoffmann, D., and Hoffmann, I. 1997. The changing cigarette, 1950-1995. J. Toxicol. Environ. Health 50:307-364.

Holmgren, A. 1985. Thioredoxin. Annu. Rev. Biochem. 54:237-271.

Hoshino, Y., Mio, T., Nagai, S., Miki, H., Ito, I., and Izumi, T. 2001. Cytotoxic effects of cigarette smoke extract on an alveolar type II cell-derived cell line. Am. J. Physiol. Lung Cell Mol. Biol. 281:L509-L516.

Hsieh, C. C., and Papaconstantinou, J. 2006. Thioredoxin-ASK1 complex levels regulate ROS-mediated p38 MAPK pathway activity in livers of aged and long-lived Snell dwarf mice. FASEB J. 20:59-68.

James, A. L., Pare, P. D., and Hogg, J. C. 1989. The mechanics of airway narrowing in asthma. Am. Rev. Respir. Dis. 139:242-246.

Kaimul Ahsan, M., Nakamura, H., Tanito, M., Yamada, K., Utsumi, H., and Yodoi, J. 2005. Thioredoxin-1 suppresses lung injury and apoptosis induced by diesel exhaust particles (DEP) by scavenging reactive oxygen species and by inhibiting DEP-induced downregulation of Akt. Free Radical Biol. Med. 39:1549-1559.

Lee, Y. J., Kim, J. H., Chen, J., and Song, J. J. 2002. Enhancement of metabolic oxidative stress-induced cytotoxicity by the thioredoxin inhibitor 1-methylpropyl 2-imidazolyl disulfide is mediated through the ASK1SEK1-JNK1 pathway. Mol. Pharmacol. 62:1409-1417.

Liu, M., Yang, S. C., Sharma, S., Luo, J., Cui, X., Peebles, K. A., Huang, M., Sato, M., Ramirez, R. D., Shay, J. W., Minna, J. D., and Dubinett, S. M. 2007. EGFR signaling is required for TGF-beta 1 mediated COX-2 induction in human bronchial epithelial cells. Am. J. Respir. Cell Mol. 37:578-588.

Martin, M. D., and Matrisian, L. M. 2007. The other side of MMPs: Protective roles in tumor progression. Cancer Metastasis Rev. 26:717-724.

Massague, J., Blain, S. W., and Lo, R. S. 2000. TGFbeta signaling in growth control, cancer, and heritable disorders. Cell 103:295-309.

Murillo, M. M., del Castillo, G., Sánchez, A., Fernández, M., and Fabregat, I. 2005. Involvement of EGF receptor and $\mathrm{c}-\mathrm{Src}$ in the survival signals induced by TGF-beta1 in hepatocytes. Oncogene 24:4580-4587.

Nakamura, H., Nakamura, K., and Yodoi, J. 1997. Redox regulation of cellular activation. Annu. Rev. Immunol. 15:351-369.

Nakamura, T., Nakamura, H., Hoshino, T., Ueda, S., Wada, H., and Yodoi, J. 2005. Redox regulation of lung inflammation by thioredoxin. Antioxid. Redox Signal. 7:60-71.

Nonn, L., Williams, R. R., Erickson, R. P., and Powis, G. 2003. The absence of mitochondrial thioredoxin 2 causes massive apoptosis, exencephaly, and early embryonic lethality in homozygous mice. Mol. Cell. Biol. 23:916-922.

Ohbayashi, H., and Shimokata, K. 2005. Matrix metalloproteinase-9 and airway remodeling in asthma. Curr. Drug Targets Inflamm. Allergy 4:177-181.

Powis, G., and Montfort, W. R. 2001. Properties and biological activities of thioredoxins. Annu. Rev. Pharmacol. 41:261-295.

Ryter, S. W., Kim, H. P., Hoetzel, A., Park, J. W., Nakahira, K., Wang, X., and Choi, A. M. 2007. Mechanisms of cell death in oxidative stress. Antioxid. Redox Signal. 9:49-89.

Sato, A., Hara, T., Nakamura, H., Kato, N., Hoshino, Y., Kondo, N., Mishima, M., and Yodoi, J. 2006. Thioredoxin-1 suppresses systemic inflammatory responses against cigarette smoking. Antioxid. Redox Signal. 8:1891-1896.

Sato, A., Hoshino, Y., Hara, T., Muro, S., Nakamura, H., Mishima, M., and Yodoi, J. 2008. Thioredoxin-1 ameliorates cigarette smoke-induced lung inflammation and emphysema in mice. J. Pharmacol. Exp. Ther. 325:380-388.

Semlali, A., Jacques, E., Plante, S., Biardel, S., Milot, J., Laviolette, M., Boulet, L. P., and Chakir, J. 2008. TGF-beta suppresses EGF-induced MAPK signaling and proliferation in asthmatic epithelial cells. Am. J. Respir. Cell Mol. Biol. 38:202-208.

Seomun, Y., Kim, J. T., and Joo, C. K. 2008. MMP-14 mediated MMP-9 expression is involved in TGF-beta1-induced keratinocyte migration. J. Cell Biochem. 104:934-941.

Sharma, S. V., Bell, D. W., Settleman, J., and Haber, D. A. 2007. Epidermal growth factor receptor mutations in lung cancer. Nat. Rev. Cancer $7: 169-181$

Sheng, G., Bernabe, K. Q., Guo, J., and Warner, B. W. 2006. Epidermal growth factor receptor-mediated proliferation of enterocytes requires p21waf1/cip1 expression. Gastroenterology 131:153-164.

Tesfaigzi, Y. 2006. Roles of apoptosis in airway epithelia. Am. J. Respir. Cell Mol. Biol. 34:537-547.

Tobiume, K., Matsuzawa, A., Takahashi, T., Nishitoh, H., Morita, K., Takeda, K., Minowa, O., Miyazono, K., Noda, T., and Ichijo, H. 2001. ASK1 is required for sustained activations of JNK/p38 MAP kinases and apoptosis. EMBO Rep. 2:222-228.

Ueno, M., Masutani, H., Arai, R. J., Yamauchi, A., Hirota, K., Sakai, T., Inamoto, T., Yamaoka, Y., Yodoi, J., and Nikaido, T. 1999. Thioredoxindependent redox regulation of p53-mediated $\mathrm{p} 21$ activation. J. Biol. Chem. 274:35809-35815.

Uttamsingh, S., Bao, X., Nguyen, K. T., Bhanot, M., Gong, J., Chan, J. L., Liu, F., Chu, T. T., and Wang, L. H. 2007. Synergistic effect between EGF and TGF-betal in inducing oncogenic properties of intestinal epithelial cells. Oncogene 27:2626-2634.

Wada, T., and Penninger, J. M. 2004. Mitogen-activated protein kinases in apoptosis regulation. Oncogene 23:2838-2849. 
Wald, N. J., and Hackshaw, A. K. 1996. Cigarette smoking: An epidemiological overview. Br. Med. Bull. 52:3-11.

Watson, W. H., Yang, X., Choi, Y. E., Jones, D. P., and Kehrer, J. P. 2004. Thioredoxin and its role in toxicology. Toxicol. Sci. 78:3-14.

Wollman, E. E., d'Auriol, L., Rimsky, L., Shaw, A., Jacquot, J. P., Wingfield, P., Graber, P., Dessarps, F., Robin, P., and Galibert, F. 1988. Cloning and expression of a cDNA for human thioredoxin. J. Biol. Chem. 263:15506-15512.

Xiong, Y., Hannon, G. J., Zhang, H., Casso, D., Kobayashi, R., and Beach, D. 1993. p21 is a universal inhibitor of cyclin kinases. Nature 366:701-704.

Yamada, T., Iwasaki, Y., Nagata, K., Fushiki, S., Nakamura, H., Marunaka, Y., and Yodoi, J. 2007. Thioredoxin-1 protects against hyperoxia-induced apoptosis in cells of the alveolar walls. Pulmon. Pharmacol. Ther. 20:650-659.

Yamasaki, M., Kang, H. R., Homer, R. J., Chapoval, S. P., Cho, S. J., Lee, B. J., Elias, J. A., and Lee, C. G. 2008. P21 regulates TGF-beta1-induced pulmonary responses via a TNF-alpha-signaling pathway. Am. J. Respir. Cell Mol. Biol. 38:346-353.
Yamauchi, K., and Inoue, H. 2007. Airway remodeling in asthma and irreversible airflow limitation-ECM deposition in airway and possible therapy for remodeling. Allergol. Int. 56:321-329.

Yao, H., Yang, S. R., Kode, A., Rajendrasozhan, S., Caito, S., Adenuga, D., Henry, R., Edirisinghe, I., and Rahman, I. 2007. Redox regulation of lung inflammation: Role of NADPH oxidase and NF-kappaB signalling. Biochem. Soc. Trans. 35:1151-1155.

Yoneda, K., Chang, M. M., Chmiel, K., Chen, Y., and Wu, R. 2003. Application of high-density DNA microarray to study smoke- and hydrogen peroxideinduced injury and repair in human bronchial epithelial cells. J. Am. Soc. Nephrol. 14:S284-S289.

Yoon, H. K., Cho, H. Y., and Kleeberger, S. R. 2007. Protective role of matrix metalloproteinase-9 in ozone-induced airway inflammation. Environ. Health Perspect. 115:1557-1563.

Yoshida, T., Oka, S., Masutani, H., Nakamura, H., and Yodoi, J. 2003. The role of thioredoxin in the aging process: Involvement of oxidative stress. Antioxid. Redox Signal. 5:563-570. 